\title{
Editorial
}

\section{Tres décadas de producción de conocimiento de Investigación y Educación en Enfermería}

\author{
María de los Ángeles Rodríguez-Gázquez \\ Enfermera. Editora en Jefe de Investigación y Educación en Enfermería. Profesora Doctora de la Universidad de Antioquia UdeA. \\ Cómo citar esta editorial en edición digital: Rodríguez-Gázquez Ma A. (2015) Tres décadas de producción de conocimiento de \\ Investigación y Educación en Enfermería. Cultura de los Cuidados (Edición digital) 19, 41. \\ Disponible en: http://dx.doi.org/10.14198/cuid.2015.41.01> \\ Correspondencia: Calle 64 \#53-09, Medellín; Colombia. \\ Correo electrónico: maria.rodriguezg@udea.edu.co \\ Recibido: 1/07/2014; Aceptado: 15/09/2014
}

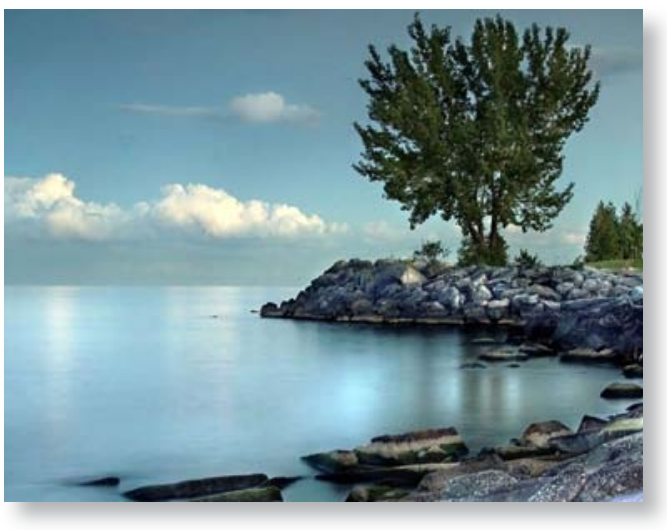

Investigación y Educación en Enfermería (IEE), es una publicación de la Facultad de Enfermería de la Universidad de Antioquia (Colombia) que tiene como misión la difusión de los avances en la investigación y en la educación que contribuyan al desarrollo de la disciplina.

Esta revista fue creada en 1983 por la necesidad de disponer de un medio escrito donde publicar los resultados de la investigación enfermera. Con el paso del tiempo, IEE se fue adecuando a las exigencias cada vez más altas dictadas a las publicaciones seriadas científicas para el reconocimiento de su calidad, por parte de organismos nacionales e internacionales, lo que la ha llevado a su inclusión en los índices nacionales e internacionales más impor- tantes como: Medline-Pubmed, SciELO Citation Index en Web of Knowledge, LATINDEX, PUBLINDEX, CUIDEN, EMCare de Elsevier, Fuente Académica de EBSCO, REDALYC, LILACS-BIREME, IMBIOMED, DOAJ, CIBERE e Index Copernicus, entre otros.

Desde 1983 a diciembre de 2014 en nuestra revista se han editado en forma ininterrumpida 69 números en los que se han compilaron 708 artículos. El número de manuscritos sometidos a evaluación ha tenido la tendencia al incremento en el tiempo, debido especialmente a tres razones: disponibilidad de envío, seguimiento y evaluación de los artículos online en 2009, aumento de dos a tres los números por volumen en 2010, y a que en 2012 el idioma de publicación de la revista cambió del español al inglés, facilitando la presentación de artículos a las enfermeras en cualquier rincón del planeta.

En los últimos cinco años los artículos originales predominan en nuestras tablas de contenido; el motivo de este comportamiento se puede explicar porque casi la totalidad de los autores proviene de la academia, tienen formación posgraduada y, en sus trabajos, se les exige cada vez más producir y divulgar conocimiento. Es necesario que en las instituciones 
formadoras de recurso humano ajustemos esta situación involucrando en los procesos de investigación a las enfermeras asistenciales, pues son ellas las que están más frecuentemente en contacto con los usuarios, y por consiguiente, no debe desaprovecharse sus aportes y valiosas experiencias en la práctica del cuidado.

Actualmente, cuando se evalúa el tipo de estudio declarado por los autores en los artículos originales se puede afirmar que en IEE hay equilibrio entre los paradigmas cuantitativo y cualitativo, lo que indicaría el interés de Enfermería por aproximarse al objeto de conocimiento con las perspectivas ofrecidas por las diversas metodologías. En particular, en los artículos producto de investigaciones cuantitativas, en nuestros artículo apreciamos la poca utilización de diseños analíticos que se acerquen más a la búsqueda de relaciones causales, por lo tanto es un reto importante para las universidades fomentar en sus profesores y estudiantes de doctorado la ejecución de investigaciones con enfoque analítico.
Algo a resaltar es que en las tres décadas que se lleva editando la revista IEE, las enfermeras han sido la población de la que más frecuente se tratan los artículos (25\% sobre las profesionales y $8 \%$ de las estudiantes), mostrando que la Enfermería, como profesión joven, es ella misma su autorreferencia.

Para IEE, un desafío muy grande que esperamos cumplir en poco tiempo es el de aumentar el número de citas recibidas en artículos de otras revistas, indicador indirecto de la repercusión que tiene en la comunidad académica el conocimiento que estamos avalando con su publicación. Otro reto, quizás el más importante de todos, es que debemos seguir esforzándonos en publicar cada vez más y mejores artículos que muestren alternativas innovadoras para resolver los problemas teóricos y prácticos del diario vivir de la enfermera, contribuyendo de esta forma al desarrollo de la Enfermería, como disciplina y como profesión. 